UDC $316.344 .32+378.4$

LBC 87.6

\title{
RUSSIAN UNIVERSITIES AFTER THE PANDEMIC: WAYS OF TRANSFORMATION
}

\author{
Sergey E. Sorokin \\ Northern (Arctic) Federal University named after M.V. Lomonosov, Arkhangelsk, Russian Federation
}

\begin{abstract}
The article is devoted to the analysis of the key challenges faced by Russian higher education during the pandemic and the prospects for its further development. The article highlights the key problems of higher education that have arisen in connection with the pandemic situation (reduced academic mobility, weakened partnerships, inability to complete research on time, reduced number of applicants, suspension of educational activities), examines the actions of governments and measures taken by universities to adapt to work in the context of the pandemic (development of appropriate legislation, provision of consulting and financial assistance, measures to support foreign students who found themselves in the country during the pandemic, etc.). Hypotheses are put forward regarding the ways of transformation of university education in the "post-covid" period, possible trends are proposed, including digitalization, changes in the content of the educational process, scientific activity, increasing the social role and the "third mission" of universities. The problems of online education, the development of digital technologies and new forms of education by teachers and students, and the creation of a new system of social and educational work corresponding to new educational formats are considered. Conclusions are drawn that the Russian higher education system as a whole has managed to overcome the difficulties that have arisen. The situation of the pandemic, on the one hand, has accelerated a number of transformational processes that began in the higher education system before it, and on the other - has revealed new challenges, the solution of which is necessary for the effective functioning of universities in force majeure situations. We should not expect a complete return of universities to the "pre-covid" situation, since certain mechanisms have been launched to accelerate the modernization of domestic higher education.
\end{abstract}

Key words: pandemic, coronavirus, university, education, "third mission".

Citation. Sorokin S.E. Russian Universities After the Pandemic: Ways of Transformation. Logos et Praxis, 2021, vol. 20, no. 1, pp. 23-30. (in Russian). DOI: https://doi.org/10.15688/lp.jvolsu.2021.1.3

УДК $316.344 .32+378.4$

ББК 87.6

\section{РОССИЙСКИЕ УНИВЕРСИТЕТЫ ПОСЛЕ ПАНДЕМИИ: ПУТИ ТРАНСФОРМАЦИИ}

\author{
Сергей Эдуардович Сорокин \\ Северный (Арктический) федеральный университет им. М.В. Ломоносова, \\ г. Архангельск, Российская Федерация
}

\footnotetext{
Аннотация. Статья посвящена анализу ключевых вызовов, с которыми столкнулось отечественное высшее образование в период пандемии, и перспектив его дальнейшего развития. Выделяются ключевые проблемы сферы высшего образования, которые возникли в связи с ситуацией пандемии: снижение академической мобильности; ослабление партнерств; невозможность окончания в срок научных исследований; снижение количества абитуриентов; приостановка образовательной деятельности. Рассматриваются действия ч правительств и меры, предпринятые университетами для адаптации к работе в условиях пандемии (разработ要 ка соответствующих законодательных актов, оказание консультационной и финансовой помощи, меры поддержки иностранных студентов, оказавшихся в стране в период пандемии и др.). Выдвигаются гипотезы относительно путей трансформации университетского образования в «постковидный» период. Среди возможных () тенденций выделены, в частности, цифровизация; изменение содержания образовательного процесса и
} 
научной деятельности; повышение социальной роли и «третьей миссии» университетов. Рассматриваются проблемы онлайн-образования, освоения преподавателями и студентами цифровых технологий и новых форм обучения, поднимаются вопросы создания новой системы социальной и воспитательной работы, соответствующей новым образовательным форматам. Делается вывод о том, что российской системе высшего образования в целом удалось преодолеть возникшие трудности. Ситуация пандемии, с одной стороны, ускорила ряд трансформационных процессов, которые начинались в системе высшего образования до нее, а с другой - выявила новые задачи, решение которых необходимо для эффективного функционирования университетов в форс-мажорных ситуациях. Не стоит ожидать полного возврата университетов к «доковидной» ситуации, поскольку были запущены определенные механизмы, направленные на ускорение процессов модернизации отечественного высшего образования.

Ключевые слова: пандемия, коронавирус, университет, образование, «третья миссия».

Цитирование. Сорокин С. Э. Российские университеты после пандемии: пути трансформации // Logos et Praxis. - 2021. - T. 20, № 1. - C. 23-30. - DOI: https://doi.org/10.15688/lp.jvolsu.2021.1.3

\section{Введение}

Продолжающаяся ситуация пандемии, вызванная распространением новой коронавирусной инфекции, привела к трансформации процессов функционирования различных социальных институтов, среди которых особо можно выделить сферу образования.

Особенностью системы образования является ее открытый характер, отсутствие жестких рамок и ограничений, а также способность к рефлексии, самообогащению и преобразованию на основе воздействия внешних и внутренних факторов трансформации. Образование представляет собой важнейшую общественную ценность, при этом процесс его развития оказывается обусловленным историческим типом общества, уровнем развития культуры, экономики, социальной сферы, зависит от текущего государственно-политического устройства, идеологических установок, а также от других внешних факторов.

В этой связи актуальным представляется анализ последствий, вызванных пандемией, которые уже произошли или произойдут в будущем, их влияния на сферу высшего образования, а также прогнозирование направлений внутренней трансформации университетов, путей их дальнейшего развития.

В образовательный процесс так или иначе вовлечены большие группы населения школьники, студенты, их родители, педагоги и сотрудники образовательных организаций. В эффективной работе образовательных институтов заинтересовано как государство, так и экономические субъекты - предприятия и организации. Именно поэтому на сохранение непрерывности и качества образования в период пандемии были направлены значительные усилия национальных правительств и международных организаций.

\section{Вызовы для высшего образования}

По данным опроса Международной ассоциации университетов основными вызовами, с которыми столкнулись университеты в период пандемии, стали:

- снижение академической мобильности $(89 \%)$;

- ослабление партнерств (59 \%);

- невозможность окончания в срок научных исследований (52 \%);

- снижение количества абитуриентов $(46 \%)$;

- приостановка образовательной деятельности (24\%) [COVID-19... web].

На уровне правительств государств университетам была оказана определенная поддержка, которая шла по следующим основным направлениям:

- разработка законодательных актов и руководств для организации онлайн-обучения и проведения вступительных или выпускных экзаменов;

- оказание консультационной и финансовой помощи вузам для обеспечения онлайнобучения;

- разработка стратегий и принятие тактических решений для оказания помощи иностранным студентам, оказавшимся в стране в период пандемии;

- разработка дополнительных законодательных (нормативных) актов, позволяющих 
иностранным студентам выезжать (приезжать) на обучение [Влияние пандемии... web].

Университеты по всему миру осознали свою социальную ответственность перед обществом и активно включились в работу по преодолению последствий пандемии.

По данным доклада «Влияние Covid-19 на высшее образование по всему миру» $52 \%$ университетов увеличили свою общественную активность; 49 \% усилили научную коммуникацию; 40 \% оказывали помощь в оказании медицинских консультаций; студенты и сотрудники $28 \%$ университетов оказывали помощь пострадавшим в ходе пандемии; $22 \%$ предоставили свои медицинские учреждения для нужд борьбы с распространением инфекции [Marinoni web].

Сегодня можно говорить о том, что эти усилия в целом достигли своей цели, при том, что был выявлен ряд проблемных точек, которые в перспективе должны стать точками развития образования в новых условиях.

Среди ключевых проблем сферы высшего образования, которые возникли в связи с ситуацией пандемии, выделяют следующие:

- необходимость оперативной корректировки нормативной базы в части определения принципов и условий дистанционного обучения, приема вступительных экзаменов и проведения итоговой государственной аттестации;

- организация обучения в дистанционном режиме, в том числе освоение необходимых технологий преподавателями и студентами;

- финансовые трудности, вызванные сокращением спектра дополнительных услуг и приносящей доход деятельности, уменьшением числа иностранных обучающихся, потребностью закупки средств дезинфекции, необходимость дополнительной государственной поддержки университетов;

- организация обучения студентов из других государств, в том числе обеспечение их доступа к образовательным ресурсам, создание комфортных условий проживания и социальной поддержки при невозможности выезда на родину;

- трудности при проведении рекрутинговой кампании;

- сворачивание программ академического обмена и реализации совместных образовательных программ [Клягин и др. 2020].
Отдельно стоит сказать о морально-психологическом состоянии как студентов, так и работников университетов в период пандемии. Как пишут Н.В. Сидячева и Л.Э. Зотова, «состояние «вынужденной самоизоляции» непривычно для нормального хода жизни человека в связи с его нестабильностью и непредсказуемостью» [Сидячева, Зотова 2020].

Люди оказались в ситуации, когда их представления о стабильности, жизненный уклад и образ поведения были в краткие сроки кардинально изменены. На фоне противоречивой информации в СМИ и развития панических настроений сохранение способности обучать и учиться потребовало значительных усилий как со стороны профессорскопреподавательского состава, так и со стороны обучающихся университетов.

Поддержание в трудовых и студенческих коллективах нормальной морально-психологической обстановки явилось одной из задач ректорского корпуса и администрации университетов.

В целом, по мнению большинства исследователей, на сегодняшний день отечественная система высшего образования (впрочем, как и многих других государств) в основном нашла пути адаптации к новой ситуации и решения большей части возникших проблем.

\section{Пути трансформации}

Вопрос, который волнует как университетское сообщество, так и общество в целом: вернется ли высшее образование на тот путь развития, по которому оно шло до пандемии, либо начнет движение по новой траектории. В этом отношении мнения исследователей разделились. Кто-то считает, что университеты вернутся в «доковидное» состояние без существенных изменений, кто-то говорит о том, что «университет уже не будет прежним» [«Массового закрытия вузов не будет»... web].

На наш взгляд, работа в условиях пандемии выступила катализатором развития тех направлений деятельности университетов, которые виделись в качестве перспективных.

Первое из таких направлений - это, безусловно, цифровизация. Одна из первых проблем, с которой столкнулись российские университеты с началом перехода на дистанци- 
онное обучение, - это отсутствие необходимых цифровых компетенций у преподавателей, сотрудников, а зачастую и у студентов. И если последние в силу возрастных особенностей достаточно быстро освоили новые технологии, то для многих преподавателей работа в удаленном формате стала серьезным испытанием. По данным авторов доклада «Высшее образование: уроки пандемии. Оперативные и стратегические меры по развитию системы», выполненного коллективами тринадцати российских университетов в ходе проведения работ по исследованию проблем и направлений развития высшего образования в период пандемии, «более $60 \%$ преподавателей редко или никогда не проводили лекции или занятия в электронном формате или формате вебинаров, 88,2 \% скептически относятся к формату дистанционного обучения, 42,7 \% считает, что электронный формат приведет через год к ухудшению качества высшего образования, а 67 \% не соглашаются с тем, что большинство занятий через год будут в онлайнформате» [Высшее образование... web].

При этом установки на включение удаленных форматов работы в образовательный процесс поступали от органов управления сферой образования достаточно давно, однако, как правило, они встречали отторжение в преподавательском сообществе.

Еще одним позитивным последствием активного освоения цифровых технологий в образовательном процессе в период пандемии стало создание в большинстве университетов необходимой технической базы.

Вместе с тем нельзя не отметить различие организационных и финансовых возможностей между «столичными» университетами и образовательными организациями российских регионов, которые повлияли на скорость и качество внедрения цифровых технологий в образовательный процесс.

Очевидно, что дистанционное обучение не сможет полностью заменить «живое» общение, и такой вариант не рассматривается ни на государственном уровне, ни самими университетами. Однако вероятной тенденцией развития высшего образования на ближайший период станет использование смешанной системы онлайн и оффлайн обучения. Это потребует от преподавателей, с одной стороны, постоянно совершенствовать содержание образовательных программ в условиях открытого доступа студентов к большому количеству информации в интернете, а с другой повышать уровень цифровой грамотности, готовности оперативно осваивать новые технологии. Безусловно, это должно получать соответствующую поддержку и поощрение со стороны руководства университетов.

Вторая тенденция, которая непосредственно связана с первой - изменение содержания образовательного процесса. Использование форматов дистанционного обучения неизбежно приведет к пересмотру принципов организации процесса обучения. Это будет связано, прежде всего, с сочетанием традиционного аудиторного режима обучения с самостоятельной работой студентов на цифровых платформах, что позволит составлять гибкий график взаимодействия преподавателя и студента, при котором студенту будет не обязательно ежедневно присутствовать в университете.

Следствием этого станет увеличение свободного времени как преподавателя, так и студента, которое может быть направлено как на дополнительное образование, так и на личностное развитие.

Кроме того, можно прогнозировать более активное использование студентами готовых онлайн-курсов. Мы помним, что в начале пандемии был открыт свободный доступ студентов к курсам лучших отечественных и зарубежных преподавателей. Это не только помогло снять проблему, но и выступило стимулом для многих преподавателей к тому, чтобы перевести свои лекции в электронный формат. На наш взгляд, онлайн-курсы могут стать дополнительным инструментом обучения по тем дисциплинам, где это представляется разумным, к примеру, по гуманитарным направлениям. Со временем получат свое развитие такие новые образовательные технологии как виртуальная и дополненная реальность, которые сделают онлайн-курсы более интерактивными и привлекательными для студентов.

Все это так или иначе приведет к пересмотру университетами своих образовательных программ, в основе которых должна лежать возможность выбора студентами курсов как из числа внутриуниверситетских, так и внешних онлайн-курсов, что, в конце концов 
должно привести к созданию системы индивидуальных образовательных траекторий, настройке образования на потребности и возможности конкретного студента.

Новые формы обучения потребуют научного осмысления и, возможно, приведут к появлению педагогических теорий, которые будут описывать процесс развития и формирования личности в новых условиях её воспитания, обучения и образования.

В ситуации сокращения времени непосредственного общения между преподавателем и студентом и, вероятно, времени нахождения студентов в кампусе по-другому должен строиться и воспитательный процесс, который является неотьемлемой частью образования. Личность педагога, наставника, специалиста сферы социальной работы является ключевой в воспитательном процессе. С другой стороны, в его основе лежит общение и совместная работа студентов. В 2020 г. большая часть студенчества испытывала нехватку «живого» общения, когда большинство студенческих культурно-массовой, спортивной направленности мероприятий были либо отменены, либо перенесены в онлайн-формат.

Выход студента в режим обучения по индивидуальной образовательной траектории, при которой он может не быть «привязанным» к конкретной группе, может создать ситуацию социальной изоляции, что, безусловно, окажет влияние на формирование его личности. В этой связи от университетов потребуется пересмотр системы социальной и воспитательной работы, которая должна быть направлена, с одной стороны, на социализацию студентов, освоение ими необходимых норм и правил жизни и поведения в обществе, активного включения в общественные процессы, а с другой - на формирование морально-этических принципов с использованием современных методик и технологий.

\section{«Третья миссия» в период пандемии}

Еще одна тенденция развития университетов связана с расширением их социальной роли, участия в жизни общества.

Ситуация пандемии актуализировала вопрос о «третьей миссии» университетов, под которой подразумевают «совокупность специфических услуг, основанных на действиях и возможностях, служащих для блага общества» [Marhl 2011]. К числу ее ключевых компонентов, как правило, относят «продолженное образование, обмен технологиями и инновациями, социальную вовлеченность», «передачу технологий, социальные обязательства и обучение в течение всей жизни» [Медушевский, Перфильева 2016], «генерирование, практическое применение знаний, получение выгоды от ресурсов за пределами академической среды» [Jongbloed 2008], «экономическое применение исследований, патентов, трансфер технологий, а в широком смысле - любую деятельность в направлении общества» [Dan 2012].

O.В. Перфильева называет «социальным участием» университета «понимание и учет общественных потребностей в обучении граждан, подготовке специалистов для конкретных отраслей производства, проведении конкретных научных исследований для решения проблем, актуальных для сообщества, на основе многостороннего взаимодействия с различными заинтересованными участниками» [Перфильева 2011, 134].

Многие исследователи видят новую «третью миссию» университетов в их участии в решении общемировых проблем, преодолении глобальных кризисов, ответах на ключевые вызовы современности.

Безусловно, пандемия, вызванная распространением новой коронавирусной инфекции, является таким вызовом, при том, что даже в случае успешного для человечества ее завершения нельзя исключать повторение подобных событий в будущем.

Последствия пандемии лежат не только в плоскости здравоохранения, демографии и экономики, они привели к определенным социальным и даже политическим трансформациям.

Университеты должны стать тем местом, в котором, с одной стороны, произойдет социально-философское осмысление происходящих процессов, а с другой - будут выработаны рекомендации по преодолению социальных кризисов, вызванных пандемией, найдены технологические решения актуальных проблем.

Для этого необходимы изменения как в образовательной, так и в научной деятельности университетов. В докладе, подготовленном инициативной группой под руководством британского ученого У. Бодмера еще в 1985 г., 
изложены концептуальные подходы к новому формату взаимоотношений между наукой и обществом. Значительная роль в нем отводится сфере образования и, в частности, университетам. Основополагающие тезисы доклада состоят в том, что «научное сообщество будет более эффективно в отстаивании своих целей, если откроет больше возможностей для обсуждения научных аспектов многих важных проблем, которые волнуют общество» [Bodmer, Collins 1986]. Для этого научное coобщество должно стать открытым для общества, в том числе, в медиапространстве.

Мы наблюдаем повышение интереса со стороны общества к научным исследованиям, поскольку граждане оказались зависимы от быстрых и эффективных научных решений, таких как, к примеру, разработка вакцины.

Это дает повод вновь обратиться к проблемам отечественной науки, которая во многом сосредоточена в университетах. В этой связи необходимы:

- дополнительная государственная поддержка научных исследований по приоритетным направлениям (здесь уже сделаны первые шаги: реализуется проект создания научно-образовательных центров мирового уровня);

- усиление взаимодействия между университетами и академическими институтами, в частности, институтами Российской академии наук, выделение финансирования для реализации проектов в рамках коллаборации;

- развитие взаимодействия с зарубежными учеными, упрощение процедуры их привлечения для работы над совместными проектами;

- реализация мер поддержки молодых ученых, формирование системы «кадрового научного лифта» студента начиная с уровня магистратуры.

\section{Заключение}

Таким образом, можно говорить о том, что ситуация пандемии, с одной стороны, ускорила ряд трансформационных процессов (инициация которых была обусловлена внедрением в систему высшего образования цифровых технологий), а с другой - выявила новые задачи, которые необходимо решать для того, чтобы обеспечить непрерывное функционирование в случае возникновения подобных форс-мажорных ситуаций.
Можно констатировать, что российской системе высшего образования удалось преодолеть возникшие трудности и обеспечить ведение образовательного процесса в дистантной форме, а также выработать алгоритмы поведения в случае возникновения похожих ситуаций в будущем. При этом возврат на исходные позиции вряд ли возможен, поскольку был принят ряд организационно-управленческих и технологических решений, открывающих путь если не к перезагрузке, то, по крайней мере, к модернизации системы высшего образования.

Дискуссии о том, какой она будет, продолжаются, однако ее ключевые векторы уже просматриваются: ускоренная цифровизация, новые подходы к образовательной политике, укрепление связи науки и экономики, современные требования к профессорско-преподавательскому составу и сотрудникам университета, новая социальная роль в рамках «третьей миссии». Если рассматривать этот кризис как возможность для развития, то такая возможность у университетов появилась.

\section{СПИСОК ЛИТЕРАТУРЫ}

Влияние пандемии... web - Влияние пандемии COVID-19 на сектор высшего образования и магистратуру: аналитический материал международный, национальный и институциональный ответ // https://www.ntf.ru/sites/ default/files/Vliyanie $\% 20$ pandemii $\% 20$ COVID-19\%20na\%20sektor\%20vysshego\% 20obrazovaniya \%20i\%20magistraturu.pdf (дата обращения: 27.01.2021).

Высшее образование... web - Высшее образование: уроки пандемии. Оперативные и стратегические меры по развитию системы // http://www.tsu.ru/upload/iblock/\%D0\%B0\% D0\%BD $\%$ D0\%B0\%D0\%BB $\%$ D0\%B8\%D1\% $82 \% \mathrm{D} 0 \% \mathrm{~B} 8 \% \mathrm{D} 1 \% 87 \% \mathrm{D} 0 \% \mathrm{~B} 5 \% \mathrm{D} 1 \% 81 \% \mathrm{D} 0 \%$ BA $\%$ D0 $\%$ B8 $\%$ D0 $\%$ B9 $\% 20 \% \mathrm{D} 0 \% \mathrm{~B} 4 \% \mathrm{D} 0 \% \mathrm{BE} \%$ $\mathrm{D} 0 \% \mathrm{BA} \% \mathrm{D} 0 \% \mathrm{BB} \% \mathrm{D} 0 \% \mathrm{~B} 0 \% \mathrm{D} 0 \% \mathrm{~B} 4 \% \mathrm{D} 0 \% \mathrm{~B} 4 \%$ $\mathrm{D} 0 \% \mathrm{BB} \% \mathrm{D} 1 \% 8 \mathrm{~F} \% \mathrm{D} 0 \% 9 \mathrm{C} \% \mathrm{D} 0 \% 9 \overline{\mathrm{E}} \% \mathrm{D} 0 \% 9 \mathrm{D}$ $\% \mathrm{D} 0 \% \mathrm{~B} 8 \% \mathrm{D} 1 \% 82 \% \mathrm{D0} \% \mathrm{BE} \% \mathrm{D} 0 \% \mathrm{~B} 32020$.pdf.

Клягин и др. 2020 - Клягин А.В. и др. Шторм первых недель: как высшее образование шагнуло в реальность пандемии. М.: НИУ ВШЭ, 2020. 112 с.

«Массового закрытия вузов не будет»... web «Массового закрытия вузов не будет». Ректор ВШЭ о трендах будущего образования // https://tass.ru/interviews/10541877 (дата обращения: 27.01.2021). 
Медушевский, Перфильева 2016-Медушевский Н.А., Перфильева O.B. Интерпретация третьей роли университетов на современном этапе // Вестник РГГУ. Серия «Политология. История. Международные отношения. Зарубежное регионоведение. Востоковедение». 2016. № 3. C. 19-31.

Перфильева 2011 - Перфильева О.В. Университет и регион: на пути к реализации третьей функции // Вестник международных организаций. 2011. № 1 (32). С. 133-144.

Сидячева, Зотова 2020 - Сидячева Н.В., Зотова Л.Э. Ситуация вынужденной самоизоляции в период пандемии: психологический и академический аспекты // Современные наукоемкие технологии. 2020. № 5. С. 218-225.

Bodmer, Collins 1986 - Bodmer W.F., Collins P.M.D. The Public Understanding of Science. Studies in Science Education. 1986. Vol. 13, № 1. P. 99.

COVID-19... web - COVID-19: Higher Education challenges and responses // https://iau-aiu.net/ Covid-19-Higher-Education-challenges-andresponses (дата обращения: 27.01.2021).

Dan 2012 - Dan M.C. The Third Mission of Universities in the Development Strategy of Vienna City. Informatica. Economica. 2012. Vol. 16, № 4. P. 49-56.

Jongbloed 2008 - Jongbloed B. Seven Indicators for Mapping University regional Interactions. ENID PRIME Indicators Conference in Oslo (Oslo, 2628 May 2008). Oslo: [s. n.], 2008. P. 32-56.

Marhl, Pausits 2011 - Marhl M., Pausits A. Third Mission Indicators for New Ranking Methodologies // Evaluation in Higher Education. 2011. № 5. P. 43-64. DOI: https:// doi.org/10.15393/j5.art.2013.1949.

Marinoni, Van Land, Jensen web-Marinoni G., Van Land H., Jensen T. The Impact of Covid-19 on Higher Education Around the World [IAU Global Survey Report] // https://www.iau-aiu.net/IMG/pdf/ iau_covid19_and_he_survey_report_final_may_ 2020.pdf(дата обращения: 27.01.2021).

\section{REFERENCES}

Impact of the COVID-19 Pandemic on the Higher Education Sector and Master's Degree Programs: Analysis International, National, and Institutional Response 2020. URL: https://www.ntf.ru/sites/ default/files/Vliyanie\%20pandemii\%20COVID-19\% $20 \mathrm{na} \% 20 \mathrm{~s}$ ekt or $\% 20$ vys shego $\% 20$ obrazovaniya\%20i\%20magistraturu.pdf (accessed 27 January 2021).

Higher Education: Lessons from the Pandemic. Operational and Strategic Measures for the
Development of the System 2020. URL: http:// www.tsu.ru/upload/iblock/\% D0\%B \% D0\%BD\%D0\%B0\%D0\%BB\%D0\%B8\%D1\% $82 \%$ D0\%B8\%D1\%87\%D0\%B5\%D1\%81\%D 0\%BA $\%$ D0\%B8\%D0\%B9\%20\%D0\%B4\%D0\% BE $\%$ D0\%BA\%D0\%BB $\%$ D0\%B0\%D0\%B4_\%D $0 \% \mathrm{~B} 4 \% \mathrm{D} 0 \% \mathrm{BB} \% \mathrm{D} 1 \% 8 \mathrm{~F} \% \mathrm{DD} 0 \% 9 \mathrm{C} \% \mathrm{D} 0 \% 9 \mathrm{E}$ $\% \mathrm{D} 0 \% 9 \mathrm{D} \% \mathrm{D} 0 \% \mathrm{~B} 8 \% \mathrm{D} 1 \% 82 \% \mathrm{D} 0 \% \mathrm{BE} \% \mathrm{D} 0 \%$ B32020 .pdf(accessed 27 January 2021).

Klyagin et al., 2020. The Storm of the First Weeks: How Higher Education Stepped into the Reality of the Pandemic. Moscow, NIU VSHE. (Sovremennaya analitika obrazovaniya, no. 6(36)).

“There Will Be no Mass Closure of Universities". HSE Rector on Trends in the Future of Education 2021. URL: https://tass.ru/interviews/10541877 (accessed 27 January 2021).

Medushevskij N.A., Perfil'eva O.V., 2016. Interpretation of the Third Role of Universities at the Present Stage. Bulletin of RSUH. Series "Political Science. History. International Relations. Foreign Regional Studies. Orientalism”, no. 3, pp. 19-31.

Perfil'eva O.V., 2011. University and Region: Towards the Implementation of the Third Function, no. 1 (32), pp. 133-144.

Sidyacheva N.V., Zotova L.E., 2020. The Situation of Forced Self-Isolation During the Pandemic: Psychological and Academic Aspects. Sovremennye naukoemkie tekhnologii, no. 5, pp. 218-225.

Bodmer W.F., Collins P.M.D., 1986. The Public Understanding of Science. Studies in Science Education, vol. 13, no. 1, p. 99.

COVID-19: Higher Education Challenges and Responses. URL: https://iau-aiu.net/Covid-19Higher-Education-challenges-and-responses (accessed 27 January 2021).

Dan M.C., 2012. The Third Mission of Universities in the Development Strategy of Vienna City. Informatica. Economica, vol. 16, no. 4, pp. 49-56.

Jongbloed B., 2008. Seven Indicators for Mapping University Regional Interactions. ENID PRIME Indicators Conference in Oslo (Oslo, 26-28 May 2008). Oslo, pp. 32-56.

Marhl M., Pausits A., 2011. Third Mission Indicators for New Ranking Methodologies. Evaluation in Higher Education, no. 5, pp. 43-64. DOI: https://doi.org/10.15393/ j5.art.2013.1949.

Marinoni G., Van Land H., Jensen T. The Impact of Covid-19 on Higher Education Around the world. IAU Global Survey Report. URL: https:// www.iau-aiu.net/IMG/pdf/iau_covid 19 _and_he_survey_report_final_may_2020.pdf (accessed 27 January 2021). 


\section{Information About the Author}

Sergey E. Sorokin, Candidate of Sciences (Politics), Associate Professor, Deputy ViceRector for Educational Activities, Northern (Arctic) Federal University named after M.V. Lomonosov, Severnoy Dviny Emb., 17, 163002 Arkhangelsk, Russian Federation, s.sorokin@narfu.ru,https://orcid.org/0000-0003-4604-0676

\section{Информация об авторе}

Сергей Эдуардович Сорокин, кандидат политических наук, доцент, заместитель проректора по образовательной деятельности, Северный (Арктический) федеральный университет им. М.В. Ломоносова, наб. Северной Двины, 17, 163002 г. Архангельск, Российская Федерация, s.sorokin@narfu.ru, https://orcid.org/0000-0003-4604-0676 